\title{
Research of visual political communication perception by youth: psychophysiological approach
}

\author{
Yulia Eremenko ${ }^{1}$, Anna Chentsova $^{1}$, and Anastasiia Kuzmenko ${ }^{2}$ \\ ${ }^{1}$ V.I. Vernadsky Crimean Federal University, 295015, Sevastopolskaya St., 21/4, Simferopol, Russia \\ ${ }^{2}$ Saint Petersburg State University of Economics, Saint Petersburg, Russia
}

\begin{abstract}
It is proposed to use objective methods to assess the perception of visual political content for planning an effective communication strategy by the actors of political power Two experiments were conducted in the work. The first one investigates the visual attention and memorization of different types of political content (memes, photographs of political leaders, photographs of political events and posters) by young people based on the oculographic method. The second experiment is aimed at studying the emotional reactions of young people to the perception of political video content of different genres: humorous, video memes, speech of a political leader and disgusting video. An adapted version of the Differentiated Emotions Scale (DES) was used for the evaluation.
\end{abstract}

\section{Introduction}

As noted by the authors Gorshkov M.K., Sheregi F.E., today's Russian youth is not characterized by complete apathy for politics, however, there is no high level of their political activity. They closely follow the information about political events in the country - $12.6 \%$; they do not follow the information about political events, but occasionally discuss them with friends and relatives $-41.9 \% ; 45.5 \%$ of young people are not interested in politics [1]. The authors also note that most young people consider remote communication via the Internet as their social and political activity [1].

Undoubtedly, the development of digital communication technologies has led to significant changes in various spheres of society, including politics. The main source of political information for young people is the Internet, which makes it a powerful medium for socialization and communicative influence from different social groups. In addition, under the influence of digitalization, possible forms of political participation have been significantly transformed. Along with traditional forms of voting, non-traditional forms of political participation have emerged, such as signing electronic petitions, writing blogs and articles on political topics, as well as their distribution on social networks, participation in Internet voting, elections and referendums, presence at virtual meetings of parties and congresses.

The Internet is an absolutely natural communication medium for the young generation. That is why the issues of its effective use for establishing an active dialogue with young people and their targeted socialization become urgent. Gorshkov M.K., Sheregi F.E. write 
that the diversification of the Internet into a media system has significantly narrowed the state's capacity to form a worldview. The process of socialization has ceased to be unidirectional: state - person, but has become more interactive and individualized: person person [1]. Consequently, gaining new knowledge about Internet communication technologies and understanding new forms and methods of interaction with young people in the virtual environment becomes more relevant.

\section{Literature review}

The proposed paper suggests considering approaches to designing effective visual political communication in social networks based on the use of psychophysiological approach. The reason for choosing this methodological approach is due to obtaining objective data on human perception. Psychophysiological methods are based on the study of unconscious physiological reactions of a person, and also make it possible to obtain information in real time.

The digital revolution has led to the development of visual content, which has become more accessible, emotional and attractive thanks to modern technologies. Visual symbols have long been a central element of political communication, and their importance has increased, as the visual environment of television has become the dominant source of political information [2]. Also, P.E. Rodkin noted that the importance of visual communications is increasingly being used in culture and politics with the growth of the information society, which multiplies their social functions [3]; moreover, they are a powerful tool for forming a reputation and carrying out communication strategies in a developed and aggressive information environment [3].

Many scientific papers on communications and political science consider the influence of visual stimuli on cognitive processes and emotional states of recipients, as well as their possibility to lead to political fate. Rafter, K., Novelli E. and Holtz-Bacha C. note that news photos have a high potential for "compression" of information, encouraging continued reading of the news, searching for information, creating emotions and encouraging civic engagement [4]. Graber D.A. demonstrated that visual images are the most important source of information designed to increase the memorability of a message and make it easier to process information [5]. Also, a number of experimental studies have proven that images contribute to a better understanding of campaigns and social movements [6].

A number of scientific papers reflect the positive impact of new media on civic engagement and political participation. Bakker T.P.'s national youth survey $(n=2409$, ages 16-24) showed that Internet use is positively associated with various forms of political participation [7]. Powell T.E., Boomgaarden H.G., de Swert K., de Vreese C.H. proved that certain press photos had a dominant influence on recipients' intentions to participate: perceptions of news images increased their desire to discuss political issues in detail, make donations, sign petitions and protest in support of actors involved in the conflict [8]. The work of Gil De Zúñiga, H., Abril Eulàlia P., Rojas H. shows that the consumption of online / offline news is positively related to their interpersonal discussion and political participation [9]. Porten-Chée, P. has proven that the use of party websites has a positive impact on voter participation [10], and Marcinkowski F., Metag J. and Gibson Rachel K., McAllister I. has pointed to their impact on voter participation [11, 12]. Min, S.-J. claims that online discussions of political issues increase participants' awareness of issues and encourage willingness to engage in politics [13].

The above review of researches suggests the importance of visualization and virtual environments in engaging youth in political discourse and participating in various forms of political and civic engagement. It enables us to view visualization as an effective political technology. 


\section{Methods of visual communication research}

The development of medialization and visual culture led to the appearance of various methodological approaches to its study. Vdovina T.V. classifies the following as basic approaches to the study of visual culture: psychoanalytic, sociocritical, deconstructive, hermeneutic, semiotic, structuralist, and discursive [14]. The author herself notes that the approaches described ultimately provide a scientific interpretation of what she sees, which is one version of reality and not a final point or absolute truth.

Considering visualization as a technology of political communication, there is a need for more objective methods of studying it, which allow forecasting and calculating the communicative efficiency in achieving political goals and objectives. At present, the most objective methods of studying human perception are neurophysiological. They include physiological methods: oculography, electrocephalography, facial coding, functional magnetic resonance imaging, and others [15] and also psychodiagnostic. The described methods are based on measuring the unconscious physiological reactions of a person to external stimuli, and also provide an opportunity to collect data in real time, which is especially valuable for studying visual communication in the natural environment.

The most important aspects of assessment in a study of visual political communication are: visual attention and interest, memorability and emotional perception. Let's consider the most common psychophysiological methods of assessment of marked cognitive processes and emotional states.

Table 1. Psychophysiological methods of evaluating visual political communication in social networks

\begin{tabular}{|c|c|c|}
\hline $\begin{array}{l}\text { Visual } \\
\text { attention } \\
\text { and interest }\end{array}$ & Emotions & Memory \\
\hline \multicolumn{3}{|c|}{ Physiological methods } \\
\hline $\begin{array}{l}\text { Eyetracker, } \\
\text { EEG* }\end{array}$ & $\begin{array}{l}\text { EEG, } \\
\text { breathing rate, facial coding, } \mathrm{EMG}^{* *}, \\
\text { ECG,*** } \\
\text { EDA****, } \\
\text { Eyetracker, } \\
\text { heart rate, } \\
\text { fMRI***** }\end{array}$ & $\begin{array}{l}\text { Eyetracker, } \\
\text { EEG }\end{array}$ \\
\hline \multicolumn{3}{|c|}{ Psychodiagnostic methods } \\
\hline & $\begin{array}{l}\text { Ch. Spielberger's questionnaire (level of personal and } \\
\text { situational anxiety), San U. Doskin's questionnaire } \\
\text { (well-being, activity, mood). Evaluation of endogenous } \\
\text { time count by the duration of an individual minute. } \\
\text { Differential Emotional Scales (DES) }\end{array}$ & $\begin{array}{l}\text { Method of } 10 \text { words } \\
\text { by Luria A.R., } \\
\text { Visual retention test } \\
\text { by Benton A.L. }\end{array}$ \\
\hline
\end{tabular}

*ECG - electrocardiography, ${ }^{* *}$ EMG - electromyography, ${ }^{* * *}$ EEG - electroencephalography, ${ }^{* * * *}$ EDA - electrodermal skin activity, $* * * * *$ fMRI - Functional magnetic resonance imaging.

Evaluation of visual attention and interest. Attracting attention to the message is the key point to start an effective communication process. In basic communication models such as AIDA (attention/or awareness - interest - desire - action), AIDMA (attention-interest-desirememory-action), ACCA (awareness-comprehension-conviction-action) the first stage is "attention". From a psychophysiological point of view, attention is a mechanism responsible for choosing information that gets preferential status over other available information [16]. Taking into account that the object of study in this paper is visual communication, the concept of "visual attention" is of special interest, which should be understood as a set of cognitive operations, mediating the choice of relevant and filtering out unnecessary information from 
saturated visual scenes [17]. Many scientific studies have shown the relationship between "attention" and "interest". Itti L., Koch C., Niebur E. suggested a hypothesis that areas or objects that observers find interesting should attract attention, that is, seem visually more significant [18]. Itti L. assumed that when no specific search goal is specified for the subject, there are no time constraints or other constraints, it is more likely that ascending stimuli will dominate attention to interesting goals [19].

Christopher M., Mihalas S., Parkhurst D., Niebur E. conducted a series of experiments to investigate the relationship between visual attention expressed by eye fixation and saccades and subjective interest. The authors found a positive correlation between the subjectively marked areas of interest and the objective data obtained from the oculographic study [20].

In visual communication research, oculographic studies have an advantage.

Evaluation of emotions. Emotions have a significant impact on decision making as well as the results of cognitive reactions such as memory or attention. In recent years, quite a lot of scientific work has been devoted to the role of emotions in politics. Scientists are concerned that people are increasingly relying on emotions in political decision making and are ignoring facts and logical judgments that can negatively affect democracy $[21,22]$. Szabo G. speaks of an emotional "turnaround" in the study of political discourse that places great emphasis on the role of emotions in creating, processing and responding to political information [23].

Brader T., in his book "Company for Hearts and Minds: How Emotional Calls Work in Political Advertising," describes research that shows the power of emotions to increase loyalty and rethink political views; he also says that fear makes recipients more receptive to information and enthusiasm can further attract supporters and push opponents away [24]. Casas, A., Webb Williams N. have obtained research results, which claim that enthusiasm, anger and fear mobilize political activism and message virality, while sadness demobilizes [25].

Memory. The memorability of a communicative message is essential in achieving the ultimate goals of political communication, be it support for a political party / leader, participation in rallies and protests. Memorability is closely related to such a concept as "fluency", which is understood as "ease" of processing information. Fluency, i.e. cognitive processing of information, happens more easily when the stimulus is already familiar and no additional effort is spent on its processing and understanding. That is why familiar brands, parties, politicians have a significant communication advantage (in case of positive perception), their choice or support becomes easier. We can say that at an early stage of information processing, familiar stimuli are more visually visible and attractive.

The work of Mancas M., Le Meur O., based on the use of Eyetracker, shows the impact of visual attention on memorability, and attempts to predict memorability depending on the visual stimulus [26]. Bylinskii Z. et al. studied internal and external factors affecting image memorability. The authors proposed a theoretical and information model to predict the memorability of a visual object depending on the content [27].

The objective of the work was to study the features of youth's perception of visual political content in social networks based on the use of psychophysiological methods.

\section{Research materials and methods}

To obtain information about types of political youth content, accounts of social networks of pro-government organizations, political parties and socio-political organizations were analyzed. Proportionally selected 1500 posts were tagged with the visual part of the message and basic behavioral statistics were collected, including indicators of communicability (comments), attractiveness (likes) and virality (reposts). Analytical data were obtained using the resource https://popsters.ru/ (Table 1). 
Table 2. Characteristics of behavioral activity indicators on perception of visual political content

\begin{tabular}{|c|c|c|c|c|c|}
\hline Content form & Quantity & Likes & Reposts & Comments & ERpost* \\
\hline \multicolumn{6}{|c|}{ Photos, graphic political content } \\
\hline Memes & 27 & 23,81 & 1,96 & 9,63 & 0,48 \\
\hline Photos of political events & 108 & 32,65 & 2,94 & 2,06 & 0,48 \\
\hline Historical photos & 40 & 10,88 & 0,70 & 0,18 & 0,37 \\
\hline Viral photos & 95 & 34,84 & 4,19 & 1,46 & 0,35 \\
\hline Text-image & 7 & 29,00 & 4,14 & 2,00 & 0,34 \\
\hline Photos of the team and leaders & 3 & 62,30 & 5,00 & 1,33 & 0,32 \\
\hline Photo report of interactive events & 182 & 26,40 & 2,60 & 0,33 & 0,27 \\
\hline Photo report of social projects & 129 & 38,67 & 1,99 & 0,89 & 0,26 \\
\hline Photo of agitation & 8 & 25,88 & 1,63 & 0,75 & 0,26 \\
\hline Posters & 625 & 20,30 & 3,61 & 0,96 & 0,24 \\
\hline Infographics & 7 & 11,29 & 2,14 & 0,00 & 0,13 \\
\hline Average & 1231 & 28,73 & 2,81 & 1,78 & $\mathbf{0 , 3 2}$ \\
\hline \multicolumn{6}{|c|}{ Political Video Content } \\
\hline Video reports of interactive events & 28 & 76,93 & 16,25 & 0,64 & 1,46 \\
\hline Video reports of political events & 25 & 38,44 & 3,76 & 0,76 & 0,32 \\
\hline Viral videos & 98 & 23,16 & 3,23 & 1,88 & 0,30 \\
\hline Video interview & 7 & 19,14 & 2,42 & 2,85 & 0,25 \\
\hline Webinar records & 29 & 14,45 & 1,38 & 1,10 & 0,18 \\
\hline Video reports of social projects & 7 & 16,29 & 3,71 & 0,43 & 0,17 \\
\hline Advertising image video clips & 26 & 19,65 & 2,77 & 1,15 & 0,15 \\
\hline Video agitation & 16 & 53,44 & 3,25 & 0,31 & 0,15 \\
\hline Average & 236 & 32,69 & 4,60 & 1,14 & $\mathbf{0 , 3 7}$ \\
\hline
\end{tabular}

* ERpost is a post engagement ratio that calculates the percentage of users who have been active on a social network in various forms, such as likes, dislikes, reposts, comments, clicks or retweets.

Table 1 shows that political video content has a higher social engagement rate $(0.37)$ than photo and graphic content $(0.32)$. The most interesting visual information for youth is video reports of interactive events, memes and photos of political events. Posters and photo reports of interactive and social events are the most frequently used in communication.

Thus, memes and photos of political events (with the highest ERpost score), posts (the most common type of content) and photos of political leaders (the least common type of content) were chosen for psychophysiological testing. The experiments were aimed at studying the visual attention of young people to the perception of various visual stimuli, as well as understanding the consistency of the results obtained with behavioral statistics.

Experiment 1: Assessment of visual perception of different types of political content (memes, photo of political events, photo of a political leader, poster) based on the oculographic method.

Design and stimuli. Four types of stimulus material were developed for the eyetrecking study, representing collages of their four different types of political content. To level out the effect of the location of the stimulus on the result, each type of content was presented once in each sector $\left(0^{\circ}-45^{\circ}\right.$ - upper left corner, $45^{\circ}-90^{\circ}$ - upper right corner, $90^{\circ}-135^{\circ}$ - lower right corner, $135^{\circ}-180^{\circ}$ - lower left corner).

General procedure. Before the beginning of the experiment, the participants were explained the task and conducted a nine-point calibration procedure. The participants were offered to view the slide sets for 20 seconds and then answer the questionnaire questions. 
Students of both sexes $(\mathrm{n}=17)$ were tested using the rules of bioethics, the average age was $19.58 \pm 0.49$ years, 17 people in total. All the test participants were right-handed people with normal vision. Before starting the experiments, the participants gave their written consent to the processing of their personal data.

Equipment. The study was carried out on the platform Gazerecorder (https://app.gazerecorder.com/), which allows to carry out the Internet tracking research based on a web camera. The stimulus material was developed using Adobe Photoshop CS3 graphics program, where the size and extension of 200 pixels/inch were corrected. The obtained data were processed using the methods of economic and statistical analysis implemented in the SPSS 23.0 software package.

Experiment 2. Evaluation of the emotional perception of political video using the adapted version of the differential emotion scale (Dissociative Experience Scale, DES, Izart et al. 1974).

Design and stimuli. Four political theme videos of different genres were selected (humorous, video memes, video performance of a political leader, and disgusting videos). The duration of the videos was 1.5 - 2 minutes.

General procedure. Students of both sexes $(n=40)$, average age $19.58 \pm 0.45$ years were tested using the rules of bioethics. Depending on the content, the subjects were divided into 4 experimental groups: the first $(\mathrm{N} 1=10)$, who watched a humorous video, the second $(\mathrm{N} 2=10)$ - video memes, $(\mathrm{N} 3=10)$ - declarative speech of a political leader, $(\mathrm{N} 4)$ - disgusting videos. The participants of the experiment were familiarized with the goals and objectives of the study and filled in the sheets of information consent. The survey was conducted before and after the demonstration of different genres of political video, which made it possible to observe the dynamics of change in the emotional response of the subjects to the stimulus presented. After the stimulus was presented, the volunteer participants answered the question about their intention to support the political leader / party on a scale (from 0 to 6), where 0 total non-support, 6 - total support.

Equipment. The questionnaires were prepared in google forms. The stimulus material was prepared using Movavi Video Suite. The data were processed using the methods of economic and statistical analysis implemented in the SPSS 23.0 software package.

\section{Research results}

Application of Gazerecorder platform for the experiment allowed to obtain thermal maps and quantitative data on the eye motor behavior of the subjects: average duration of fixation (Dwell time), time of the first fixation. The results of the experiment are shown in Table 2.

Table 3. Results of the oculographic experiment in the context of visual perception of political content and memorability survey

\begin{tabular}{|c|c|c|c|c|c|c|}
\hline $\begin{array}{l}\text { Content } \\
\text { presentation } \\
\text { sectors by areas } \\
\text { of interest } \\
(\text { AOIs*) }\end{array}$ & $\begin{array}{l}\text { Type of } \\
\text { political } \\
\text { content }\end{array}$ & $\begin{array}{l}\text { Average } \\
\text { fixation } \\
\text { time, } \quad 0-5 \\
\text { sec. }\end{array}$ & $\begin{array}{l}\text { Average } \\
\text { fixation } \\
\text { time, } 0-20 \\
\text { sec. }\end{array}$ & $\begin{array}{l}\text { First } \\
\text { fixatio } \\
\mathrm{n}(\mathrm{sec})\end{array}$ & $\begin{array}{l}\text { Memora } \\
\text { bility of } \\
\text { text } \\
\text { informat } \\
\text { ion }\end{array}$ & $\begin{array}{l}\text { Image } \\
\text { memor } \\
\text { ability }\end{array}$ \\
\hline \multicolumn{7}{|c|}{ Stimulus 1} \\
\hline $0^{\circ}-45^{\circ}$ & $\begin{array}{l}\text { Photo of } \\
\text { political } \\
\text { leader }\end{array}$ & 2,25 & 4,87 & 0,8 & 0 & 1 \\
\hline $45^{\circ}-90^{\circ}$ & $\begin{array}{l}\text { Political } \\
\text { meme }\end{array}$ & 1,29 & 3,99 & 2,2 & 1 & 0 \\
\hline $90^{\circ}-135^{\circ}$ & Poster & 0,29 & 2,78 & 1,82 & 0 & 1 \\
\hline
\end{tabular}


Table 3. Continued

\begin{tabular}{|c|c|c|c|c|c|c|}
\hline $135^{\circ}-180^{\circ}$ & $\begin{array}{l}\text { Photo of } \\
\text { political } \\
\text { event }\end{array}$ & 0,74 & 3,45 & 0,79 & 1 & 0 \\
\hline \multicolumn{7}{|c|}{ Stimulus 2} \\
\hline $0^{\circ}-45^{\circ}$ & $\begin{array}{l}\text { Political } \\
\text { meme }\end{array}$ & 2,86 & 5,32 & 0,52 & 1 & 3 \\
\hline $45^{\circ}-90^{\circ}$ & $\begin{array}{l}\text { Photo of } \\
\text { political } \\
\text { leader }\end{array}$ & 1,27 & 4,54 & 1,54 & 0 & 2 \\
\hline $90^{\circ}-135^{\circ}$ & $\begin{array}{l}\text { Photo of } \\
\text { political } \\
\text { event }\end{array}$ & 0,51 & 4,87 & 2,4 & 0 & 0 \\
\hline $135^{\circ}-180^{\circ}$ & Poster & 0,85 & 2,7 & 0,68 & 0 & 0 \\
\hline \multicolumn{7}{|c|}{ Stimulus 3} \\
\hline $0^{\circ}-45^{\circ}$ & $\begin{array}{l}\text { Photo of } \\
\text { political } \\
\text { event }\end{array}$ & 2,31 & 4,67 & 0,55 & 0 & 1 \\
\hline $45^{\circ}-90^{\circ}$ & Poster & 1,39 & 2,55 & 2,1 & 2 & 0 \\
\hline $90^{\circ}-135^{\circ}$ & $\begin{array}{l}\text { Photo of } \\
\text { political } \\
\text { leader }\end{array}$ & 0,79 & 2,99 & 1,96 & 0 & 0 \\
\hline $135^{\circ}-180^{\circ}$ & $\begin{array}{l}\text { Political } \\
\text { meme }\end{array}$ & 0,52 & 5,45 & 0,94 & 2 & 7 \\
\hline \multicolumn{7}{|c|}{ Stimulus 4} \\
\hline $0^{\circ}-45^{\circ}$ & Poster & 2,18 & 3,67 & 0,54 & 0 & 1 \\
\hline $45^{\circ}-90^{\circ}$ & $\begin{array}{l}\text { Photo of } \\
\text { political } \\
\text { event }\end{array}$ & 1,23 & 3,53 & 1,72 & 0 & 0 \\
\hline $90^{\circ}-135^{\circ}$ & $\begin{array}{l}\text { Political } \\
\text { meme }\end{array}$ & 1,09 & 4,86 & 1,43 & 2 & 1 \\
\hline $135^{\circ}-180^{\circ}$ & $\begin{array}{l}\text { Photo of } \\
\text { political } \\
\text { leader }\end{array}$ & 0,87 & 4,79 & 0,82 & 4 & 0 \\
\hline
\end{tabular}

* Areas of Interests;

Analysis of data on the time of the first fixation showed the trajectory of viewing visual political stimuli (Fig. 2).

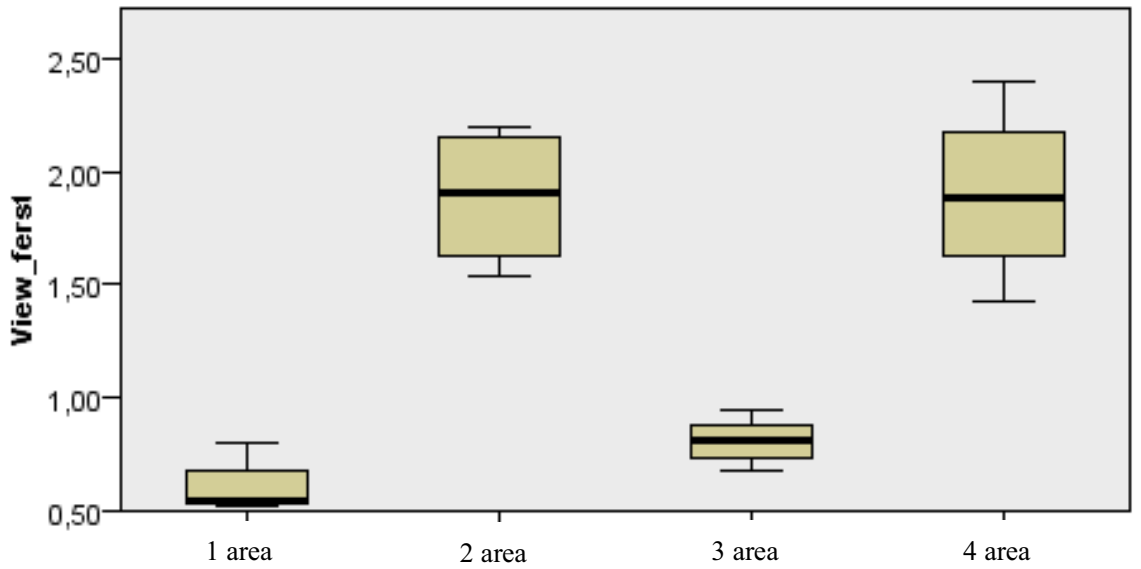

Fig. 1. Quartile diagram of the visual stimuli study trajectory 
* 1 area $-0^{\circ}-45^{\circ}, 2$ area $-45^{\circ}-90^{\circ}, 3$ area $-135^{\circ}-180^{\circ}, 4$ area $-90^{\circ}-135^{\circ}$.

The figure shows that the subjects begin to study the stimulus material by viewing the image in the upper left corner $\left(0^{\circ}-45^{\circ}\right.$, ) and then viewing the lower left corner $\left(135^{\circ}-180^{\circ}\right.$, regardless of the type of content.

Next, let's look at the effect of the type of content on the average duration of fixation. To compare the quantitative attributes of four independent samples by type of content (political meme, poster, photo of a politician, and political event), let us use the non-parametric Craskel-Wallis criterion. The calculated level of statistical significance for the CraskelWallis criterion using SPSS allowed us to reject the zero statistical hypothesis and to conclude that the average duration of fixations for different types of political content is different $(\mathrm{H}=8.201, \mathrm{df}=3, \mathrm{p}=0.042)$. To understand which groups are different, let us make paired comparisons using the Mann-Whitney criterion. A statistical significance level below 0.5 was found when comparing groups 1 (poster) and 2 (political meme), and 1 (poster) and 3 (photo of political leader), indicating statistically significant differences between these groups. The graphical representation of the average duration of fixations for all compared groups is shown in Figure 3.

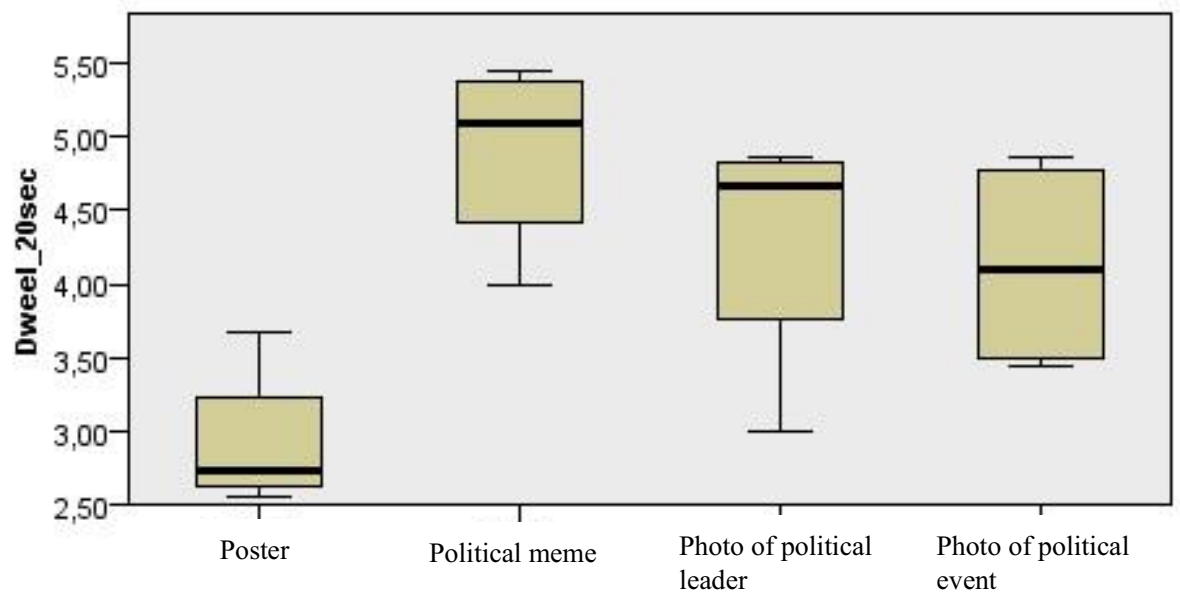

Fig. 2. Quartile diagram of the average duration of fixations on different types of political content.

The results of the memorability analysis of the presented stimuli are shown in Table 3.

Table 4. Evaluation of memorability of visual political stimuli

\begin{tabular}{|l|l|l|}
\hline Types of political content & $\begin{array}{l}\text { Memorability of text } \\
\text { information }\end{array}$ & Image memorability \\
\hline Political meme & 6 & 11 \\
\hline Photo of political leader & 4 & 3 \\
\hline Poster & 2 & 2 \\
\hline Photo of political event & 1 & 1 \\
\hline
\end{tabular}

In addition, it was found that the average duration of fixation on a content entails its memorability (image), as indicated by the Pearson correlation coefficient $(\mathrm{r}=0.564, \mathrm{p}=0.023)$. The survey was conducted immediately after the experiment, which allows us to speak about the results of short-term memory.

The second experiment was related to the analysis of emotional perception of political video content, which, by using visual and audio sensory systems, can provide quite strong emotional reactions. The analysis of changes in young people's psychological reactions to political video content revealed some changes (Table 4). 
Table 5. Comparative characteristics of emotional state (based on the results of differential emotions scale) of participants before and after viewing political content

\begin{tabular}{|c|c|c|c|c|c|c|c|}
\hline \multirow{2}{*}{$\begin{array}{l}\text { Political } \\
\text { Content }\end{array}$} & \multicolumn{3}{|c|}{ Input data } & \multicolumn{3}{|c|}{ After the experiment. } & \multirow{2}{*}{$\begin{array}{l}\text { Evaluation of intention } \\
\text { to support political } \\
\text { leader / draft law } \\
\text { (from } 0 \text { to } 6 \text { points) }\end{array}$} \\
\hline & PEI & ENE & ADEI & PEI & ENE & ADEI & \\
\hline Humorous video & 23 & 18,6 & 16,2 & 26,2 & 19,6 & $12,3^{*}$ & 2,4 \\
\hline Video memes & 21,8 & 15,2 & 11,9 & 20,6 & 18,4 & 10,9 & 1,5 \\
\hline $\begin{array}{l}\text { Video speech by } \\
\text { political leader }\end{array}$ & 26,1 & 19,5 & 14,8 & 24,9 & 18,8 & $12,1 * *$ & 2,9 \\
\hline Disgusting videos & 23,6 & 18,7 & 14,9 & 23,7 & 30,4 & 19,8 & 2,3 \\
\hline
\end{tabular}

Note. PEI - positive emotions index, ENE - extremely negative emotions index, ADEI - anxietydepressive emotions index, ${ }^{*} \mathrm{p}=0,02$ (Wilcoxon criteria), ${ }^{* *} \mathrm{p}=0,027$ (Wilcoxon criteria).

The results of psychodiagnostic testing showed that the humor and declarative promises of politicians in young people reduce the level of anxiously depressive emotions (fear, shame, guilt). Besides, the speech of a political leader has the highest rating of the intention to support him.

\section{Conclusions}

The work used psychophysiological approaches to the study of content depending on its type. The received results of physiological and psychodiagnostic experiments gave the chance to receive objective data on youth's perception of visual political stimuli presented in social networks.

The results of the experiments made it possible to adjust the overall communication strategy for promoting political accounts in social networks, which is currently observed in Russia; posters, which are the most common type of content (625), show the lowest rate of social activity and do not cause significant visual attention and interest. Pictures of political leaders' faces are practically not represented in youth accounts, but behavioral and physiological data obtained indicate their effectiveness for communication purposes and objectives. A leader, as a strong brand of political structure, is perceived "easily". We can talk about the existence of conceptual (cognitive) fluency of its perception, which leads to greater probability of memorability of information and visual attention. The analysis of the existing communication approach to promotion in social media shows insignificant use of video content, which has the highest indicators of social activity and can cause strong emotions.

Further, there is interest in more directed research of political content depending on the framing, color perception of messages, as well as the study of visual and emotional triggers of political communication. Other interesting activities include evaluating the use of new forms and types of content, such as games, movies / cartoons, music videos, life hacks, comic strips, streaming and live videos, challenges, collages and parodies, insider information, anecdotes or longreads that are practically not used in modern communication strategy.

\section{Acknowledgements}

The reported study was funded by RFBR and EISR, project number 20-011-33033» («Principles of constructing youth political communication in social networks of methods and algorithms of neurophysiology»). 


\section{References}

1. M.K. Gorshkov, F.E. Sheregi, Youth of Russia in the mirror of sociology. By the results of many years of research, 688 (2020)

2. D. Schill, Review of Communication, 12(2), 118 (2012)

3. P. Rodkin, Visual politics. Corporate style of Russia, 160 (2007)

4. K. Rafter, E. Novelli, C. Holtz-Bacha, In Europawahlkampf 2014: Internationale Studien zur Rolle der Medien, 35 (2016)

5. D.A. Graber, Journal of Communication, 40(3), 134 (1990)

6. C. Corrigall-Brown, R. Wilkes, American Behavioral Scientist, 56(2), 223 (2012)

7. T.P. Bakker, C.H. de Vreese, Communication Research, 38(4), 451 (2011)

8. T.E. Powell, H.G. Boomgaarden, K. de Swert, C.H. de Vreese, Journal of Communication, 65(6), 997 (2015)

9. H. Gil De Zúñiga, P. Abril Eulàlia, H. Rojas, New Media \& Society, 11(4), 553 (2009)

10. P. Porten-Chée, Journal of Information Technology \& Politics, 10(3), 25 (2013)

11. F. Marcinkowski, J. Metag, Publizistik, 58(1), 23 (2013)

12. K. Gibson Rachel, I. McAllister, Political Communication, 28(2), 227 (2011)

13. S.-J. Min, Journal of Computer-Mediated Communication, 12(4), 87 (2007)

14. T.V. Vdovina, Bulletin of the Peoples' Friendship University of Russia. Series: Sociology, 1, 16 (2012)

15. Yu.A. Eremenko, O.N. Ulanovskaya, Marketing in Russia and abroad, 2, 37 (2020)

16. H. Plassmann, Zoëga T. Ramsøy, M. Milosavljevic, Journal off Consumer Psychology, 22(1), 18 (2012)

17. S.A. McMains, S. Kastner, Encyclopedia of Neuroscience (2009)

18. L. Itti, C. Koch, E. Niebur, IEEE Transactions on Pattern Analysis and Machine Intelligence, 20(11), 1254 (1998)

19. L. Itti, Visual Cognition, 12(6), 1093 (2005)

20. M. Christopher, S. Mihalas, D. Parkhurst, E. Niebur, Journal of Vision, 9(11), 25, 1 (2009)

21. C. Crouch, British Academy Blog (2017), https://www.thebritishacademy.ac.uk/

22. J. Moss, E. Robinson, J. Watts, Political Studies, 68(4), 837 (2020)

23. G. Szabo, East European Journal of Society and Politics, 6(2), 5 (2020)

24. T. Brader, American Journal of Political Science 49(2), 388 (2005)

25. A. Casas, N. Webb Williams, Political Research Quarterly, 72(2), 75 (2018)

26. M. Mancas, O. Le Meur, Conference: 20th IEEE International Conference on Image Processing (ICIP) (2013)

27. Z. Bylinskii, P. Isola, C. Bainbridge, A. Torralba, A. Oliva, Vision Research, 116, Part B, 165 (2015) 